\section{Diagnosis of large granular lymphocytic leukemia in a patient previously treated for acute myeloblastic leukemia}

\author{
Sinem Civriz Bozdag, ${ }^{1}$ \\ Sinem Namdaroglu, ${ }^{1}$ Omur Kayikci, \\ Gülsah Kaygusuz, ${ }^{2}$ Itir Demiriz, ${ }^{1}$ \\ Murat Cinarsoy, ${ }^{1}$ Emre Tekgunduz, ${ }^{1}$ \\ Fevzi Altuntas ${ }^{1}$ \\ 'Ankara Oncology Education and \\ Research Hospital, Hematology and Stem \\ Cell Transplantation Clinic, Ankara; \\ 2Pathology Department, Ankara \\ University School of Medicine, Ankara, \\ Turkey
}

\begin{abstract}
Large granular lymphocytic (LGL) leukemia is a lymphoproliferative disease characterized by the clonal expansion of cytotoxic $\mathrm{T}$ or natural killer cells. We report on a patient diagnosed with T-cell LGL leukemia two years after the achievement of hematologic remission for acute myeloblastic leukemia.
\end{abstract}

\section{Introduction}

Large granular lymphocytic (LGL) leukemia is a lymphoproliferative disease characterized by clonal expansion of cytotoxic $\mathrm{T}$ or natural killer (NK) cells. One-third of patients are asymptomatic, while the remaining two-thirds have symptoms related to neutropenia, anemia or autoimmune diseases such as rheumatoid arthritis. ${ }^{1-3}$

Although, previously, higher numbers of large granular lymphocytes were required for diagnosis, the currently accepted criteria include patients with LGL counts of more than $0.5 \times 10^{9} / \mathrm{L}$ for at least six months. ${ }^{4,5}$ T-cell LGL leukemia is an indolent disease, whereas NKcell LGL leukemia mostly demonstrates an aggressive course. ${ }^{6,7}$

\section{Case Report}

We report a patient diagnosed with T-cell LGL leukemia two years after the achievement of hematologic remission for acute myeloblastic leukemia (AML). A 57-year old male patient presented with weakness and fever. Physical examination showed fever of $38^{\circ} \mathrm{C}$, pallor and hepatosplenomegaly. Complete blood count (CBC) showed; white blood cell (WBC) count $45 \times 10^{9} / \mathrm{L}$, absolute neutrophil count (ANC)
$0.014 \times 10^{9} / \mathrm{L}$, hemoglobin (Hb) $9 \mathrm{gr} / \mathrm{dL}$, platelets (Plt) $43 \times 10^{9} / \mathrm{L}$. Peripheral blood smear showed $90 \%$ of the cells were myeloblasts and thrombocyte counts were consistent with CBC. Flow cytometry analysis revealed $93 \%$ blasts with the following antigens: MPO+, CD34-, HLA DR-, CD33+, CD38+, CD117+, CD64-, CD14-, CD13-, CD 7-. Cytogenetic analysis was $46, \mathrm{XY}$. He was diagnosed as AML not otherwise specified (NOS). Induction therapy $(7+3)$ was started and at Day 3 of chemotherapy, Klebsiella and Candida cruse $i$ were grown in sputum culture. Thorax high-resolution computerized tomography revealed peribronsial thickness and ground glass appearance in the lower lobes of both lungs in addition to a $1.5 \times 1$ $\mathrm{cm}$ diameter nodule that was detected in the right upper lobe. Serum galactomannan levels were in the normal range. Abdominal ultrasonography showed hepatomegaly and hypodens nodular areas (largest $2.5 \times 3.5 \mathrm{~cm}$ ) in spleen. Bone marrow aspiration biopsy was performed on Day 28 of chemotherapy and the patient was found to be in hematologic remission. Despite antifungal treatment, fever and nodules in spleen persisted so splenectomy was performed for differential diagnosis. Pathological examination of spleen revealed congestion but no fungal infection.

During follow up, fever was under control and consolidation therapy with high-dose ARAC (6 $\mathrm{g} / \mathrm{m}^{2}$ Days 1,3 and 5) was started. The third consolidation treatment was complicated with Wernicke encephalopathy and treated with intravenous thiamine supplementation. This therapy led to a partial recovery but the patient could not proceed with subsequent consolidation treatment due to poor performance status. Paraparesia continued and physical therapy was scheduled; this improved the patient's motor weakness. At the sixteenth month of his follow up in remission, leukocytosis was observed in $\mathrm{CBC}$ without any systemic complaints except weakness in both legs. CBC results were: WBC $16 \times 10^{9} / \mathrm{L}$, ANC $4.5 \times 10^{9} / \mathrm{L}$, lympohcytes $11 \times 10^{9} / \mathrm{L}$, Plt $226 \times 10^{9} / \mathrm{L}$, and $\mathrm{Hb}$ $14 \mathrm{gr} / \mathrm{dL}$. Peripheral blood smear was consistent with $\mathrm{CBC}$ and $60 \%$ of the leukocytes were made up of large granular lymphocytes. In flow cytometry analysis of peripheral blood, $57 \%$ of leukocytes were lymphocytes and $89 \%$ of lymphocytes were T cells. Seventy-two percent of T cells were LGL; $98 \%$ of them expressed TCR alpha beta and $2 \%$ of them expressed TCR gama delta. Clonality of T cells were also confirmed by multiplex PCR analysis. Chest-abdomen-pelvis tomography revealed no lymphadenopathy. Rheumatoid factor and antinuclear antibody (ANA) levels were found to be negative. As the patient did not have any complaints due to LGL counts or any kind of autoimmune disease, he was followed up without treatment. At the 26th month of follow up, he is still in hematologic remission for AML diagnosis. His
Correspondence: Sinem Civriz Bozdag, Ankara Oncology Education and Research Hospital, Hematology and Stem Cell Transplantation Clinic, Demetevler-Yenimahalle 06200 Ankara, Turkey.

Tel. +90.312.336.0909 -7271 - Fax: +90.312 .335 .3818$ E-mail: scivriz@hotmail.com

Key words: large granular lymphocytic leukemia, acute myeloblastic leukemia.

Contributions: the authors contributed equally.

Conflict of interests: the authors declare no potential conflict of interests.

Received for publication: 16 September 2013. Accepted for publication: 17 October 2013.

This work is licensed under a Creative Commons Attribution NonCommercial 3.0 License (CC BYNC 3.0).

(C) Copyright S.C. Bozdag et al., 2013

Licensee PAGEPress, Italy

Hematology Reports 2013; 5:e14

doi:10.4081/hr.2013.e14

blood counts are stable and he still does not have any complaints except weakness in both his legs.

\section{Discussion}

Large granular lymphocytes are the cells which undergo apoptosis after contact with an infected cell. These cells are either CD3- NK or CD3+ T cells. ${ }^{8}$ The LGL clone has been shown to manifest in the context of an initially polyclonal immune response or an autoimmune process. $^{4}$ The majority $(80-90 \%)$ of patients with T-LGL leukemia show a CD3+CD8+CD57+CD56-CD28-, TCR- + phenotype. $^{2}$

Clonality of T LGL is mostly demonstrated by TCR- PCR analyses. Flow cytometric T-cell receptor $\mathrm{V}$ repertoire analysis can also be used for diagnosis of a clonal T-cell population. ${ }^{9,10}$

One of the largest series published from France revealed that $51 \%$ of LGL leukemia patients were diagnosed with hyperlymphocytosis. ${ }^{5}$ Neutropenia was found to be more frequent than anemia and thrombocytopenia. Severe neutropenia was associated with recurrent infections. ${ }^{11}$ Our patient was not neutropenic or anemic when he was diagnosed but his lymphocyte count was more than $10 \times 10^{9} / \mathrm{L}$. Rheumatoid factor and antinuclear antibodies can be detected in patients with LGL leukemia and autoimmune diseases such as rheumatoid artritis. Rheumatoid factor and ANA levels were normal in our patient and there were no 
symptoms that could be related to any autoimmune disease. Splenomegaly ranged from $19 \%$ to $50 \%$ in different series. ${ }^{4,12}$ Splenectomy was reported to be a valid therapeutic option in cases of T- LGL leukemia with splenomegaly and refractory cytopenia. ${ }^{12}$ Interestingly, in our patient, increase in the LGL count appeared approximately two years after splenectomy.

Reactive T-cell lymphoproliferation can be associated with malignancies. There are case reports of B-cell chronic lymphocytic leukemia, splenic lymphoma with villous lymphocytes, hairy cell leukemia, monocloncal gammopathy of undetermined significance (MGUS), and multiple myeloma associated with LGL leukemia. ${ }^{13-15}$ In a French cohort, myelodysplasia and B-cell lymphoid neoplasms were diagnosed in $17 \%$ and $5 \%$ of patients, respectively. Only 2 patients were diagnosed as AML in this study. Autoreactive T cells were held responsible for the pathogenesis of T-LGL and association with aplastic anemia or myelodysplastic syndrome. But the exact pathogenesis of other hematologic malignancies and T-LGL must still be explained. All these neoplasms were reported to present from six to 16 years before the diagnosis of LGL proliferation. ${ }^{5}$ In our patient, LGL proliferation progressed in the second year of AML diagnosis and despite splenectomy.

The majority of LGL leukemia patients are symptomatic at the time of presentation. In a French cohort, $44 \%$ of the patients required treatment during follow up. ${ }^{5}$ But since our patient was asymptomatic except for weakness in his legs, for the moment we have not started any therapy.

\section{Conclusions}

In conclusion, we report a patient diagnosed as LGL leukemia two years after the achievement of hematologic remission of AML and splenectomy. Concurrent AML and LGL leukemia diagnosis is extremely rare and our case is also interesting because of the occurence of LGL leukemia after splenectomy which is a modality used for its treatment.

\section{References}

1. Liu X, Loughran TP Jr. The spectrum of large granular lymphocyte leukemia and Felty's syndrome. Curr Opin Hematol 2011;18:254-9.

2. Sokol L, Loughran TP Jr. Large granular lymphocyte leukemia. Oncologist 2006;11: 263-73.

3. Lamy T, Loughran TP. Clinical features of large granular lymphocyte leukemia. Seminin Hematol 2003;40:185-95.

4. Lamy T, Loughran TP Jr. How I treat LGL leukemia. Blood 2011;117:2764-74.

5. Bareau B, Rey J, Hamidou M, et al. Analysis of a French cohort of patients with large granular lymphocyte leukemia: a report on 229 cases. Haematologica 2010;95:1534-41.

6. Pandolfi F, Loughran TP Jr., Starkebaum G, et al. Clinical course and prognosis of the lymphoproliferative disease of granular lymphocytes: a multicenter study. Cancer 1990;65:341-8.

7. Suzuki R, Suzumiya J, Nakamura S, et al.
Aggressive natural killer-cell leukemia revisited: large granular lymphocyte leukemia of cytotoxic NK cells. Leukemia 2004;18:763-70.

8. Watters RJ, Liu X, Loughran TP Jr. T-cell and natural killer-cell large granular lymphocyte leukemia neoplasias. Leuk Lymphoma 2011;52:2217-25.

9. Zhang D, Loughran TP Jr. Large granular lymphocytic leukemia: molecular pathogenesis, clinical manifestations, and treatment. ASH Education Book 2012;1:652-9.

10. Hsieh YC, Chang ST, Huang WT, et al. A comparative study of flow cytometric T cell receptor $\mathrm{V}$ repertoire and $\mathrm{T}$ cell receptor gene rearrangement in the diagnosis of large granular lymphocytic lymphoproliferation. Int J Lab Hematol 2013;35:501-9.

11. Loughran TPJr. Clonal diseases of large granular lymphocytes. Blood 1993;82:1-14.

12. Subbiah V, Viny AD, Rosenblatt $\mathrm{S}$, et al. Outcomes of splenectomy in T-cell larg granular lymphocyte leukemia with splenomegaly and cytopenia. Exp Hematol 2008;36:1078-83.

13. Hanada T, Ishida T, Kojima H, Tsuchiya T. Granular lymphocyte leukemia in association with multiple myeloma. Br J Haematol 1992;80:127-9.

14. Papadaki T, Stamopoulos K, Kosmas C, et al. Clonal T-large granular lymphocyte proliferations associated with clonal B cell lymphoproliferative disorders. Report of eight cases. Leukemia 2002;16: 2167-9.

15. Lesveve JF, Feugier P, Lamy T. Association of B-chronic lymphocytic leukemia and Tlarge granular lymphocyte leukemia. Clin Lab Haematol 2000;22:121-2. 